\title{
Interactions between the dorsal and the ventral pathways in mental rotation: An fMRI study
}

\author{
HIDEYA KOSHINO \\ Carnegie Mellon University, Pittsburgh, Pennsylvania \\ and California State University, San Bernardino, California
}

and

\author{
PATRICIA A. CARPENTER, TIMOTHY A. KELLER, and MARCEL ADAM JUST \\ Carnegie Mellon University, Pittsburgh, Pennsylvania
}

\begin{abstract}
In this fMRI study, we examined the relationship between activations in the inferotemporal region (ventral pathway) and the parietal region (dorsal pathway), as well as in the prefrontal cortex (associated with working memory), in a modified mental rotation task. We manipulated figural complexity (simple vs. complex) to affect the figure recognition process (associated with the ventral pathway) and the amount of rotation $\left(0^{\circ} \mathrm{vs} .90^{\circ}\right)$, typically associated with the dorsal pathway. The pattern of activation not only showed that both streams are affected by both manipulations, but also showed an overadditive interaction. The effect of figural complexity was greater for $90^{\circ}$ rotation than for $0^{\circ}$ in multiple regions, including the ventral, dorsal, and prefrontal regions. In addition, functional connectivity analyses on the correlations across the time courses of activation between regions of interest showed increased synchronization among multiple brain areas as task demand increased. The results indicate that both the dorsal and the ventral pathways show interactive effects of object and spatial processing, and they suggest that multiple regions interact to perform mental rotation.
\end{abstract}

The focus of the present study was to investigate a relationship between the dorsal and the ventral streams in high-level visual cognition. We used fMRI to examine how large-scale networks of cortical regions associated with spatial rotation and perceptual encoding are modulated by two variables: the degree of mental rotation and the complexity of the figure being rotated. The main components of the network to be examined include the left and right intraparietal regions (part of the dorsal stream or the so-called where system), the left and right inferior extrastriate (IES) and inferior temporal regions (part of the ventral or what stream; see, e.g., Mishkin, Ungerleider, \& Macko, 1983; Ungerleider \& Haxby, 1994), and the frontal system, which has been implicated in studies of visual and spatial working memories.

The theoretical perspective is based on the hypothesis that fMRI-measured activation is a correlate of resource consumption in a resource-based computational architecture and that more difficult tasks tend to require the

A portion of this study was reported at the 2001 Annual Meeting of the Psychonomic Society, Orlando, FL. This research was supported by Office of Naval Research Grant N00014-02-1-0037 and National Institute for Neurological Diseases and Stroke Grant P01NS35949. The authors thank Vladimir Cherkassky, Robert Mason, and Sharlene Newman for helpful comments on the manuscript and Victor A. Stenger for assistance with the spiral fMRI pulse sequence. Correspondence concerning this article should be addressed to H. Koshino, Department of Psychology, California State University, 5500 University Parkway, San Bernardino, CA 92407 (e-mail: hkoshino@csusb.edu). consumption of more resources (Just, Carpenter, \& Varma, 1999). In this perspective, fMRI activation provides a measure of cognitive workload. As support for these hypotheses, several studies have shown that fMRI-measured activation systematically varies with manipulations of task difficulty (cognitive workload) in domains as diverse as sentence comprehension (e.g., Just, Carpenter, Keller, Eddy, \& Thulborn, 1996; Keller, Carpenter, \& Just, 2001), n-back tasks (e.g., Braver, Cohen, Jonides, Smith, \& Noll, 1997; Grasby et al., 1994) and mental rotation (e.g., Carpenter, Just, Keller, Eddy, \& Thulborn, 1999; Cohen et al., 1996; Tagaris et al., 1997). The general argument is that the neural implementation of a process requires physiological resources, such as the neuronal, circulatory, and glial processes, as well as structural connectivity that ensures the coordinated communication of the networks that subserve the visuospatial experiences. The fMRI activation measure is interpreted as assessing one facet of the involvement of the large-scale neural networks (Mesulam, 1990, 1998) that correlate with cognitive computations.

The study focuses on three cortical areas associated with visuospatial processing. The first, the where system, is a processing stream that projects from the occipital cortex to the parietal region and that participates in the computation of extrapersonal and personal spatial localization (e.g., Mishkin et al., 1983; Ungerleider \& Haxby, 1994). This system is thought to be involved in mental rotation, because the task requires the computation of the spatial coordinates of the object being mentally rotated 
and its comparison with the represented coordinates of the target object. A graded fMRI study of mental rotation in which the Shepard and Metzler (1971) task was used showed that increases in the amount of rotation, from $0^{\circ}$ to $120^{\circ}$, are associated with linearly increasing amounts of activation in the left and right intraparietal sulcus (IPS; Carpenter et al., 1999). This result was obtained even when the self-paced trial times were equated to the duration of the $0^{\circ}$ condition, indicating that the result is not simply due to time on task. Also, a control condition suggested that eye movements per se contributed minimally to the result, the control involving scanning between two grids so that the magnitude and number of eye movements exceeded those in the highest rotation condition. Finally, activation around the IPS occurs during mental rotation even when the input is auditory, so it is not dependent on the processing of visual input (Just, Carpenter, Maguire, Diwadkar, \& McMains, 2001).

Other neuroimaging and event-related potential (ERP) studies also implicate this region. In a study involving the Shepard-Metzler rotation task, fMRI-measured activation was found in the left and right parietal regions (Brodmann areas [BAs] $7 \mathrm{a}$ and $7 \mathrm{~b}$ and, sometimes, BA 40) when a rotation condition was compared with a $0^{\circ}$ rotation condition (e.g., Cohen et al., 1996; Tagaris et al., 1997). A PET study showed activation in the left posterior-superior parietal cortex when activation during the mental rotation of letters was compared with a condition requiring a simple discrimination of normal and mirror-image upright letters (Alivisatos \& Petrides, 1997). Parietal involvement has also been found in three ERP studies of a simpler rotation task in which participants judged whether a letter was normal or mirror-imaged (Desrocher, Smith, \& Taylor, 1995; Peronnet \& Farah, 1989; Wijers, Otten, Feenstra, Mulder, \& Mulder, 1989). As the angular disparity increased, there was increasing negativity in the ERP waveforms in the latency range of $350-800 \mathrm{msec}$, particularly in the parietal and occipital leads, which was interpreted as reflecting rotation. Thus, manipulating the mental rotation workload should affect the activation in parietal regions.

In addition to mental rotation, the effect of figural complexity, which is hypothesized to affect figural encoding, was examined in this study. The so-called what system is associated with a stream that includes the occipital region, the IES regions, and the inferior temporal gyrus (Ungerleider \& Mishkin, 1982). Numerous functional neuroimaging studies of visual object recognition have shown activation in the inferior temporal cortex (e.g., Kanwisher, Chun, McDermott, \& Ledden, 1996; Malach et al., 1995). Also, lesions in this area can correlate with impaired shape-based visual recognition or visual agnosia (Farah, 1990). Microelectrode studies with macaque monkeys have also shown activation associated in the homologous regions in shape-based visual recognition studies (Logothetis, Pauls, \& Poggio, 1995). None of these studies suggests that these patterns of activity occur independently of activity in other cortical regions. Indeed, there is evidence that both the infe- rior temporal and the IPS regions show increased activation if the recognition of objects from line drawings is made more difficult by deleting line contours (Diwadkar, Carpenter, \& Just, 2000).

A third cortical area of interest includes the frontal regions that are associated with maintaining and operating on spatial and visual information over short time periods, often referred to as spatial working memory (e.g., Levy \& Goldman-Rakic, 2000; Miller, Erikson, \& Desimone, 1996; Owen et al., 1998; Petrides, 1994). Several brainimaging studies have investigated the hypothesis that the prefrontal cortex is organized according to types of information, such as spatial versus verbal information (e.g., Smith, Jonides, \& Koeppe, 1996) and spatial versus object information (D'Esposito, Aguirre, Zarahn, \& Ballard, 1998; Levy \& Goldman-Rakic, 2000). Other studies have been done to examine whether the prefrontal cortex can be divided into functional subcomponents on the basis of types of operations, such as maintenance versus manipulation (e.g., D'Esposito, Postle, Ballard, \& Lease, 1999; Petrides, 1994). But none of the proposed dichotomies gives completely dissociated activation (Carpenter, Just, \& Reichle, 2000; D'Esposito et al., 1999). In the present study, we examined how prefrontal activation might show sensitivity to variables that impact on two types of visuospatial processes, figural encoding and rotation.

Previous theorizing about the relationship between figural complexity and mental rotation has been based largely on behavioral studies in which it has been hypothesized that the figural encoding and the rotation processes are relatively independent of each other, since it had been found that rate of rotation is not affected by figural complexity (Cooper, 1975). We considered two possible hypotheses in examining these issues with respect to brain activation. One was the independent pathway hypothesis based on Cooper's conclusion. If the amount of rotation and figural complexity affect processes that are independent of each other, the manipulation of stimulus complexity should primarily affect the activation of the regions in the ventral pathway, and the rotation manipulation should primarily affect the parietal regions in the dorsal pathway. On the other hand, previous studies in our laboratory had demonstrated that logically separable processes can show an overadditive interaction when combined. For example, in language comprehension, Keller et al. (2001) examined the effects of lexical frequency and syntactic complexity, processes that were hypothesized to operate on different levels, which resulted in an overadditive interaction in numerous cortical regions, suggesting that the two types of processes draw on a shared infrastructure of resources. Therefore, the relationship between the dorsal and the ventral pathways may be interactive (interactive pathway hypothesis), and both the complexity and the rotation manipulations may affect both the IES and the parietal regions.

We were also interested in examining the temporal aspects of processing by measuring correlations of the activation time series between regions of interest (ROIs) within various conditions. Such analyses can be inter- 
preted as reflecting the functional connectivity between cortical regions. The rationale behind this type of analysis is that regions that work together should have similar activation time series profiles, and therefore, a correlation coefficient between these regions' activation across the time course should be high (e.g., Friston, 1994; Friston, Frith, Liddle, \& Frackowiak, 1993; McIntosh \& Gonzalez-Lima, 1994). Functional connectivity was investigated with exploratory factor analyses (e.g., Peterson et al., 1999). The basic idea behind factor analyses was that if some regions have higher correlations across the time course, they should be extracted as factors. In this case, the factors should represent large-scale cortical networks (Mesulam, 1990, 1998). We specifically examined whether the functional connectivity between pairs of activated regions increased as the task increased in difficulty. A previous study (Diwadkar et al., 2000) showed that the functional connectivity between frontal and parietal areas in a spatial working memory task increased with the working memory load. If functional connectivity increases as task difficulty increases, as was shown in Diwadkar et al., one might predict that factor structures grow larger as task difficulty increases. In other words, many more brain areas might show correlated activity as cognitive workload increases.

\section{METHOD}

\section{Participants}

The participants were 11 ( 5 females) right-handed volunteer students at Carnegie Mellon University, whose mean age was 21.0 years $(S D=2.0)$. Each participant gave signed, informed consent (approved by the University of Pittsburgh and the Carnegie Mellon Institutional Review Boards). The participants were familiarized with the scanner, the fMRI procedure, and the mental rotation task before the study commenced.

\section{Stimuli}

The stimulus figures were the random polygons originally developed by Attneave and Arnoult (1956) and modified by Cooper (1975; Cooper \& Podgorny, 1976), with examples shown in Figure 1 . The present stimuli were either simple ( 6 and 8 points) or complex (16 and 24 points), for two levels of complexity. Variations in the original standard stimuli had been scaled by Cooper and Podgorny to generate six evenly spaced deviations from a standard figure (s), indicated as d 1 to $\mathrm{d} 6$. The levels of similarity among stimuli were controlled by utilizing $\mathrm{d} 1, \mathrm{~d} 3$, and $\mathrm{d} 5$ for the 6- and 16-point figures and s, d2, and $\mathrm{d} 4$ for the 8- and 24-point figures, for a total of six different stimuli.

\section{Procedure}

The design consisted of two within-subjects factors: the amount of rotation $\left(0^{\circ}\right.$ and $\left.90^{\circ}\right)$ and figural complexity (simple and complex figures). In each trial, two stimulus figures were presented side by side, simultaneously. The paradigm involved a blocked design with five trials of a single condition per block, resulting in 45-sec blocks. There were two repetitions of each condition in separate blocks during the first and second halves of a single scanning run lasting about $15 \mathrm{~min}$. The order of the conditions (including two nonsimultaneous conditions that are not reported here) was randomized within each half of the paradigm; this same order was used for all the participants. Across the two blocks of each condition, half of the correct responses were same, and half were different. Blocks of experimental conditions were separated by a 6-sec rest interval. In addition, there were four blocks of a 24-sec fixation condition, during which an $\mathrm{X}$ was presented at the center of the display and the participant was asked to fixate the $\mathrm{X}$ without doing anything else. This condition occurred at the beginning of the experiment, was repeated after every four blocks of experimental trials, and was used to measure baseline brain activation.

Each trial began with presentation of an X to be fixated for $1 \mathrm{sec}$, followed by two stimulus figures presented side by side to the right and left of the fixation point. The stimuli remained on for $9 \mathrm{sec}$ regardless of the participant's response. The participant was asked to decide as quickly as possible whether the two figures were the same or different and was told to press the right-hand button if they were the same and the left-hand button if they were different.

The stimuli were projected onto a viewing screen attached within the bore of the scanner and were viewed at a distance of approximately $20 \mathrm{~cm}$ from the participants' eyes through two mirrors positioned on top of the head coil. At this distance, each of the figures subtended a visual angle of approximately $10^{\circ}$. Two fiber optic button boxes were used by the participants to signal their responses. Stimulus presentation and behavioral data collection were controlled with custom-written experimental presentation software using Windows Workstation NT. The participants were given eight blocks of five trials on the day before the scan, and three practice trials in the scanner at the beginning of the session

\section{Imaging Parameters}

Scanning was done in a 3.0T GE Medical Systems scanner (Thulborn et al., 1996) at the University of Pittsburgh Magnetic Resonance Research Center. A T2*-weighted single-shot spiral pulse sequence with blood oxygen level dependent (BOLD; see Kwong et al., 1992; Ogawa, Lee, Kay, \& Tank, 1990) contrast was used with the following acquisition parameters: $\mathrm{TR}=1,000 \mathrm{msec}, \mathrm{TE}=18 \mathrm{msec}$, flip angle $=70^{\circ}$, FOV $=20 \times 20 \mathrm{~cm}$, matrix size $=64 \times 64$, axialoblique plane with 16 slices, and a voxel size of $3.125 \times 3.125 \times$ $5 \mathrm{~mm}$ with a 1-mm gap. High-resolution T1-weighted structural images were acquired with a $3 \mathrm{D}$ SPGR volume scan with the following parameters: $\mathrm{TR}=25, \mathrm{TE}=4$, flip angle $=40^{\circ}, \mathrm{FOV}=24 \times$ $18 \mathrm{~cm}, 124$ slices, resulting in voxel dimensions of $0.9375 \times$ $0.9375 \times 1.5 \mathrm{~mm}$ thick, taken axially.

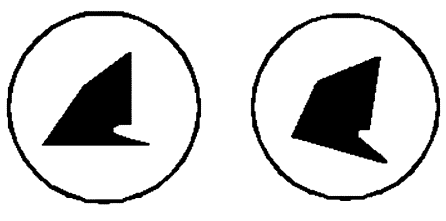

Simple
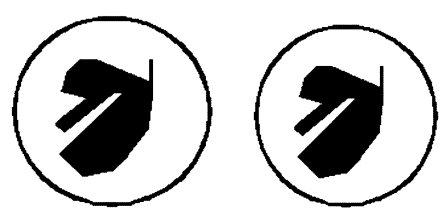

Complex

Figure 1. Stimulus figures that were used in the mental rotation task. 


\section{fMRI Data Analysis}

Image preprocessing (including baseline correction, mean correction, motion correction, and trend correction) was performed using FIASCO (Eddy, Fitzgerald, Genovese, Mockus, \& Noll, 1996; Lazar, Eddy, Genovese, \& Welling, 2001; further description and tools are available at www.stat.cmu.edu/ fiasco/). The maximum in-plane displacement estimate between individual images and a reference image did not exceed 0.3 voxels. Data from the 6 -sec rest interval and from the first $6 \mathrm{sec}$ of each block of trials were discarded to accommodate the rise and fall of the hemodynamic response (Bandettini, Wong, Hinks, Tikofsky, \& Hyde, 1992). Voxelwise $t$ tests were computed to compare a voxel's mean signal intensity in each experimental condition with that in the fixation condition. Detection of activation was accomplished by thresholding the resulting $t$ maps at $t>5.0$, which is slightly more conservative than the Bonferroni-corrected $p<.05$ level for the approximately 10,000 voxels in all the ROIs we examined. The main dependent measure was the number of voxels activated above this threshold. We also computed the average percentage of difference in signal intensity (dsi) across activated voxels over the average intensity for the baseline condition, which is reported in the Appendix.

To compare the volume of activation across the experimental conditions, anatomical ROIs were defined individually for each participant by adapting the parcellation scheme of Rademacher and his colleagues (Caviness, Meyer, Makris, \& Kennedy, 1996; Rademacher, Galaburda, Kennedy, Filipek, \& Caviness, 1992), as is shown in Figure 2. This method uses limiting sulci and coronal planes, defined by anatomical landmarks, to segment cortical regions. Because each individual's cortical anatomy is different, the ROIs were drawn on the structural images of each participant to target the anatomical ROI. This was done by first computing the mean functional image for each of the functional slices. These mean images were then registered, in parallel alignment with the anterior-commissureposterior-commissure line, to a structural volume scan of each participant. The limiting sulci and other anatomical landmarks were then located by viewing the structural images simultaneously in the three orthogonal planes, and the ROIs were defined by manually tracing the regions onto the axial image of each structural slice and then transferring them to the same locations in the coregistered functional slices. The ROIs were edited with reference to the functional mean image, in order to correct for differences in susceptibility artifacts between the structural and the functional images. Because these distortions were severe in the inferior slices of the frontal and temporal lobes, frontal and temporal ROIs were omitted from the most inferior two to four slices on an individual basis.

The interrater reliability of this ROI-defining procedure between two trained staff members was previously evaluated for four ROIs in 2 participants in another study (Just et al., 2001). The reliability measure was obtained by dividing the size of the set of voxels that overlapped between the two raters by the mean of their two set sizes. The resulting eight reliability measures were in the $78 \%-91 \%$ range, with a mean of $84 \%$, as high as the reliability reported by the developers of the parcellation scheme. This method allows us to measure the modulation of the activation by the independent variables in regions that are specified a priori and requires no morphing for definition.

The ROIs were as follows: the dorsolateral prefrontal cortex (DLPFC), the frontal eye field (FEF), the inferior frontal gyrus (IFG), the posterior precentral sulcus (PPREC), the superior medial frontal paracingulate (SMFP), the superior parietal lobule (SPL), the IPS, the inferior parietal lobule (IPL), the supramarginal gyrus (SGA), the inferior temporal lobule (IT), the superior extrastriate (SES), the IES, the calcarine fissure (CALC), and the occipital pole (OP).

To statistically analyze the number of activated voxels, the data were submitted to a 2 (hemisphere) $\times 2$ (amount of rotation) $\times 2$ (stimulus complexity) within-subjects analysis of variance (ANOVA) for each ROI that has separate left- and right-hemisphere regions. For each ROI that does not have the left and the right hemispheres represented separately (the anterior cingulate, the supplementary motor area, the SMFP, the CALC, and the OP), the data were submitted to a 2 (amount of rotation) $\times 2$ (stimulus complexity) withinsubjects ANOVA.

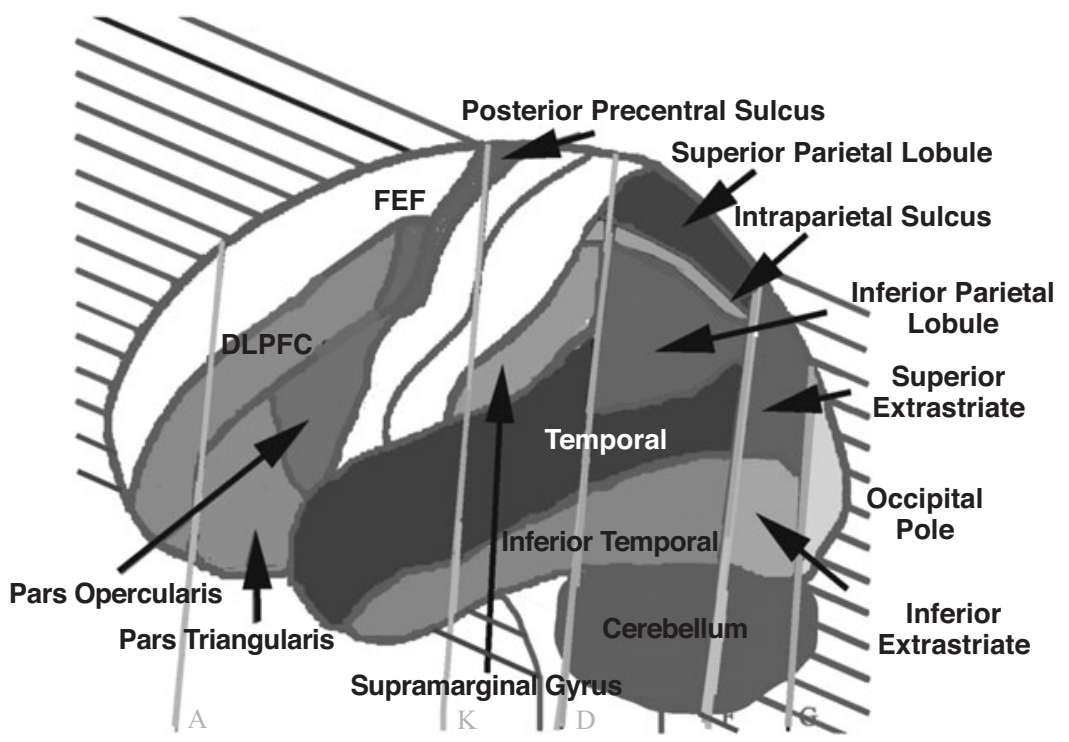

Figure 2. A schematic diagram indicating the regions of interest (ROIs) that were individually parcellated for each participant in the present study. The cortical parcellation scheme was adapted from Caviness, Meyer, Makris, and Kennedy (1996) but collapses a number of parcellation units into single broad ROIs and identifies the region in and around the intraparietal sulcus as a single ROI. DLPFC, dorsolateral prefrontal cortex; FEF, frontal eye field. 


\section{Functional Connectivity}

We computed a measure of functional connectivity, the comodulation or synchronization between the time courses of signal intensity for the activated voxels in various ROIs. Briefly, the processed data were Fourier interpolated in time to correct for the interleaved slice acquisition sequence. A mean signal intensity of the activated voxels in each ROI was then computed across the time course for each of the experimental conditions. This analysis was based only on observations associated with the task and did not include observations associated with the rest condition. The analysis was done separately for each ROI with three or more activated voxels for each participant (see Figure 3 for an example of how the activation levels in two areas tend to track each other and how the magnitudes of correlation coefficients do not necessarily depend on the levels of signal intensity). Then a correlation coefficient of signal intensity across the time course was computed between two ROIs after the data from the fixation condition were removed. The mean correlations (averaged across participants) between the ROIs were computed after Fisher's $z$ transformation, and a correlation matrix was created for each condition. An ROI pair was included in the correlation matrix if both of the two ROIs for the ROI pair had three or more mean activated voxels for the most difficult condition, which was the complex $90^{\circ}$ rotation condition. Therefore, the size of the original correlation matrix was controlled for the four experimental conditions in the beginning. Then an exploratory factor analysis was performed (e.g., Peterson et al., 1999) for each condition, to examine which ROIs were grouped with each other. Our assumption behind the factor analyses was that each factor represents a large-scale network among brain regions that are correlated or described as corresponding to some functions (e.g., Mesulam, 1990, 1998). Factors were extracted with the principal component analysis and were rotated with the varimax method. Factors that had eigenvalues of 1.0 or above were retained (an eigenvalue corresponds to the equivalent number of ROIs that the factor represents), and ROIs that had factor loadings of .4 or greater were taken into consideration in interpretation (factor loadings represent the degree to which each of the ROIs correlates with each of the factors). According to this rule, the original factor analysis extracted eight factors for the simple $0^{\circ}$, four factors for the complex $0^{\circ}$, four factors for the simple $90^{\circ}$, and four factors for the complex $90^{\circ}$ conditions. We further excluded factors consisting of two ROIs, because we were interested in large-scale networks. This resulted in three factors for the simple $0^{\circ}$, three factors for the complex $0^{\circ}$, and three factors for the complex $90^{\circ}$ conditions. The number of factors for the simple $90^{\circ}$ condition remained four.

\section{RESULTS}

\section{Behavioral Data}

Mean reaction times (RTs) and error rates are shown in Table 1. RTs were longer for $90^{\circ}$ of rotation than for $0^{\circ}[F(1,10)=79.48, p<.001]$ and longer for the complex figures than for the simple figures $[F(1,10)=49.21, p<$ $.001]$. In addition, the effect of stimulus complexity was greater for the $90^{\circ}$ of rotation condition than for $0^{\circ}$, resulting in a significant interaction between the amount of rotation and complexity $[F(1,10)=5.6, p<.05]$. The participants also made more errors for $90^{\circ}$ of rotation than for $0^{\circ}[F(1,10)=20.12, p<.01]$. However, there was no effect of stimulus complexity $[F(1,10)=0.03$, n.s. $]$ and no interaction $[F(1,10)=0.01$, n.s. $]$ for the error rates.

\section{fMRI Data}

The analysis focused on whether the amount of activation is additive or interactive. The results showed overadditive interactions between object complexity and mental
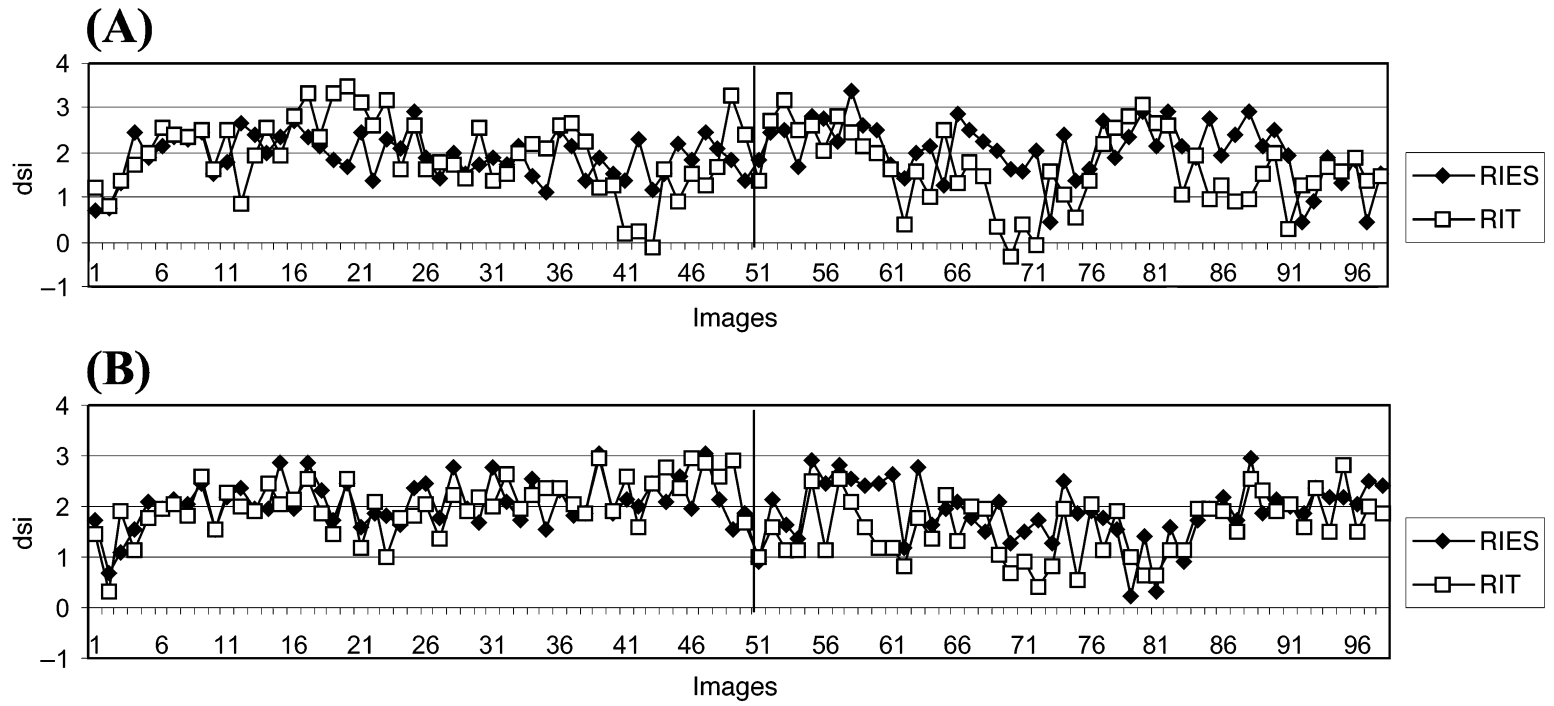

Figure 3. An example of a correlated activation time course in two regions of interest (ROIs) from 1 participant. In this figure, the percentage of signal increase (dsi) of the right inferior extrastriate (RIES) and the right inferior temporal (RIT) for (A) the complex $0^{\circ}$ rotation condition $[r(96)=0.29, p<.05]$ and $(\mathrm{B})$ the complex $90^{\circ}$ rotation condition $[r(96)=0.60, p<.001]$ were plotted against image number. Even though the mean dsi is the same for the two conditions (mean dsi is 1.97 for RIES and 1.79 for RIT for complex $0^{\circ}$ rotation, and mean dsi is 1.98 for RIES and 1.80 for RIT for complex $90^{\circ}$ rotation), the correlation coefficient was much higher for the complex $90^{\circ}$ rotation condition. These results indicate that the correlation does not necessarily depend on the amount of activation. The vertical line marks the end of the first block. The images corresponding to the fixation condition were excluded from the computation of the correlation coefficient. 
Table 1

Mean Reaction Times (RTs, in Milliseconds) and Error Rates (in Percentages)

\begin{tabular}{|c|c|c|c|c|c|c|c|c|}
\hline \multirow{3}{*}{$\begin{array}{c}\text { Amount of } \\
\text { Rotation }\end{array}$} & \multicolumn{4}{|c|}{ Simple } & \multicolumn{4}{|c|}{ Complex } \\
\hline & \multicolumn{2}{|c|}{ RT } & \multicolumn{2}{|c|}{ Error Rate } & \multicolumn{2}{|c|}{$\mathrm{RT}$} & \multicolumn{2}{|c|}{ Error Rate } \\
\hline & $M$ & $S D$ & $M$ & $S D$ & $M$ & $S D$ & $M$ & $S D$ \\
\hline $0^{\circ}$ & 2,221 & 721.6 & 7.3 & 10.1 & 2,569 & 658.1 & 7.3 & 9.1 \\
\hline $90^{\circ}$ & 2,851 & 815.2 & 24.5 & 11.3 & 3,669 & 948.2 & 25.5 & 18.6 \\
\hline
\end{tabular}

rotation in many ROIs. The $90^{\circ}$ mental rotation produced more brain activation than the $0^{\circ}$ condition did, and this effect of rotation was greater for the complex figures than for the simple figures. The number of activated voxels in each ROI is shown in Table 2 with the Talairach coordinates (Talairach \& Tournoux, 1988) of the mean centroid, averaged across the four experimental conditions, and the results of the ANOVA are given in Table 3. Examples of ROIs showing the overadditive interaction are given in Figures 4 and 5. As is shown in Figure 5, the overadditive interaction was significant $[F(1,10)=14.94$, $p<.01$, for the DLPFC; $F(1,10)=7.82, p<.05$, for the IPS; and $F(1,10)=11.47, p<.01$, for the IES].

A second important aspect of the result is that this overadditive interaction was present in a majority of the ROIs. It was present in all the regions of primary interest: the IPS, the inferior temporal and occipital regions, and the frontal areas (see Table 3 for statistics). However, the patterns of the overadditive interactions were not the same across these ROIs. As Table 2 shows, for the frontal, temporal, and occipital regions, the effect of the amount of rotation was observed only for the complex stimuli, but not for the simple stimuli. However, for the parietal regions, activation increased from $0^{\circ}$ to $90^{\circ}$ of rotation even for the simple stimuli but increased much more for the complex stimuli. As can be seen in Table 3, there was no three-way interaction. Very similar results were found on the second dependent measure, the average percentage of dsi, shown in the Appendix.

Although most ROIs showed bilateral activation, for some manipulations there was more activation in one hemisphere, often in the right hemisphere. The effect of the amount of rotation was greater for the right hemisphere than for the left in the DLPFC $[F(1,10)=9.99$, $p<.05]$ and the IFG $[F(1,10)=9.86, p<.05]$. The effect of figural complexity was greater for the right hemisphere than for the left in the IFG $[F(1,10)=6.0, p<.05]$. The brain activation was bilateral in the parietal regions. In the occipital region, the complexity effect was greater for the left hemisphere than for the right in the SES $[F(1,10)=8.84, p<.05]$. There was no significant threeway interaction.

One might wonder, however, whether the results are confounded with duty cycle issues; in other words, could the higher activation for the more difficult condition be due to the longer RT. To examine these issues, we analyzed the pattern of activation, using only the first $3 \mathrm{sec}$ of each trial with the same threshold and ANOVA design as in the original analysis. The results of the analysis show substantially the same patterns of significant results in the major ROIs, such as the DLPFC, the IPS, and the IES, as those reported for the main analysis. Therefore, it does not seem that the duty cycle issue had much effect on the results.

The pattern of results was also robust across a range of thresholds. We analyzed the data with both a lower threshold $(t=4.5)$ and a higher threshold $(t=5.5)$, to determine whether the pattern of activation is specific to

Table 2

Mean Activated Voxels for Conditions and Their Mean Centroids for Each Region of Interest

\begin{tabular}{|c|c|c|c|c|c|c|c|c|c|c|c|c|c|c|}
\hline \multirow[b]{3}{*}{ Region } & \multicolumn{8}{|c|}{ Mean Activated Voxels } & \multicolumn{6}{|c|}{ Mean Centroids } \\
\hline & \multicolumn{4}{|c|}{ Left Hemisphere } & \multicolumn{4}{|c|}{ Right Hemisphere } & \multicolumn{3}{|c|}{ Left Hemisphere } & \multicolumn{3}{|c|}{ Right Hemisphere } \\
\hline & $\mathrm{S} 0^{\circ}$ & $\mathrm{C}^{\circ}$ & $\mathrm{S} 90^{\circ}$ & $\mathrm{C} 90^{\circ}$ & $\mathrm{S}^{\circ}$ & $\mathrm{C}^{\circ}$ & $\mathrm{S} 90^{\circ}$ & $\mathrm{C} 90^{\circ}$ & $x$ & $y$ & $z$ & $x$ & $y$ & $z$ \\
\hline \multicolumn{15}{|l|}{ Frontal } \\
\hline Dorsolateral prefrontal cortex & 5.8 & 4.3 & 4.0 & 8.6 & 7.8 & 6.0 & 7.1 & 17.6 & 34 & -35 & 29 & -34 & -28 & 36 \\
\hline Frontal eye field & 1.2 & 1.2 & 1.6 & 4.2 & 3.7 & 5.0 & 5.4 & 7.9 & 44 & -1 & 42 & -43 & -2 & 40 \\
\hline Inferior frontal gyrus & 1.6 & 1.3 & 1.3 & 2.6 & 5.0 & 4.6 & 6.2 & 10.2 & 44 & -17 & 20 & -43 & -12 & 24 \\
\hline Posterior precentral sulcus & 3.2 & 3.3 & 5.2 & 8.5 & 2.5 & 2.6 & 2.9 & 7.2 & 38 & 6 & 47 & -38 & 7 & 51 \\
\hline Supplementary motor area & 0.7 & 0.5 & 0.6 & 1.5 & & & & & -3 & 12 & 65 & & & \\
\hline Superior medial frontal paracingulate & 3.5 & 2.8 & 2.2 & 6.6 & & & & & -5 & -15 & 56 & & & \\
\hline \multicolumn{15}{|l|}{ Parietal } \\
\hline Inferior parietal lobule & 3.5 & 4.4 & 5.6 & 9.6 & 3.6 & 3.7 & 5.6 & 7.6 & 40 & 53 & 42 & -40 & 58 & 36 \\
\hline Intraparietal sulcus & 12.3 & 15.7 & 22.0 & 32.9 & 16.1 & 21.2 & 29.2 & 41.8 & 26 & 62 & 44 & -31 & 62 & 42 \\
\hline Superior parietal lobule & 6.5 & 8.7 & 13.2 & 20.7 & 7.4 & 10.8 & 12.6 & 19.5 & 16 & 64 & 54 & -23 & 62 & 51 \\
\hline \multicolumn{15}{|l|}{ Temporal } \\
\hline Inferior temporal lobule & 6.1 & 5.5 & 9.1 & 13.2 & 13.7 & 13.6 & 16.1 & 22.6 & 43 & 64 & 1 & -42 & 64 & -3 \\
\hline \multicolumn{15}{|l|}{ Occipital } \\
\hline Inferior extrastriate & 12.7 & 10.7 & 15.1 & 24.6 & 14.0 & 17.0 & 16.9 & 26.3 & 28 & 75 & -3 & -25 & 76 & -4 \\
\hline Superior extrastriate & 5.0 & 6.1 & 6.5 & 13.6 & 7.1 & 7.5 & 9.0 & 12.6 & 22 & 83 & 25 & -24 & 81 & 23 \\
\hline Calcarine fissure & 11.6 & 8.7 & 9.5 & 13.2 & & & & & -5 & 77 & 8 & & & \\
\hline Occipital pole & 16.1 & 16.6 & 18.8 & 23.6 & & & & & -2 & 92 & 8 & & & \\
\hline
\end{tabular}

Note-Mean centroids were computed across four conditions. The supplementary motor area, the superior medial frontal paracingulate, the calcarine fissure, and the occipital pole are medial ROIs and are not separated between the left and the right hemispheres. S, simple; C, complex. 
Table 3

Results of Analyses of Variance on the Mean Activated Voxels (Rotation Amount [2] $\times$ Complexity [2] $\times$ Hemisphere [2])

\begin{tabular}{|c|c|c|c|c|c|c|c|}
\hline Region & Amount & Complexity & Hemisphere & $\mathrm{A} \times \mathrm{C}$ & $\mathrm{A} \times \mathrm{H}$ & $\mathrm{C} \times \mathrm{H}$ & $\mathrm{A} \times \mathrm{C} \times \mathrm{H}$ \\
\hline \multicolumn{8}{|l|}{ Frontal } \\
\hline Dorsolateral prefrontal cortex & $14.74^{* *}$ & 3.48 & 2.60 & $14.94^{* *}$ & $9.99^{*}$ & 3.94 & 2.10 \\
\hline Frontal eye field & $6.02^{*}$ & 3.83 & $5.73^{*}$ & $7.41^{*}$ & 0.34 & 0.87 & 0.71 \\
\hline Inferior frontal gyrus & 3.41 & $6.79^{*}$ & 3.11 & $8.59^{*}$ & $9.86^{*}$ & $6.00^{*}$ & 4.26 \\
\hline Posterior precentral sulcus & $5.16^{*}$ & $4.59^{\dagger}$ & 0.53 & $7.03^{*}$ & 1.62 & 0.50 & 0.27 \\
\hline Supplementary motor area & 2.12 & 1.58 & NA & 2.38 & NA & NA & NA \\
\hline Superior medial frontal paracingulate & 2.66 & $4.86^{\dagger}$ & NA & $5.50^{*}$ & NA & NA & NA \\
\hline \multicolumn{8}{|l|}{ Parietal } \\
\hline Inferior parietal lobule & $7.23^{*}$ & $8.93^{*}$ & 0.33 & $4.71^{\dagger}$ & 0.87 & 1.38 & 0.27 \\
\hline Intraparietal sulcus & $25.18^{* * *}$ & $12.61^{* *}$ & 3.76 & $7.82^{*}$ & 3.27 & 2.55 & 0.00 \\
\hline Superior parietal lobule & $14.57^{* *}$ & $8.21^{*}$ & 0.01 & 4.34 & 1.62 & 0.10 & 1.26 \\
\hline \multicolumn{8}{|l|}{ Temporal } \\
\hline Inferior temporal lobule & $14.03^{* *}$ & $10.26^{* *}$ & $8.38^{*}$ & $6.72^{*}$ & 0.07 & 1.48 & 0.30 \\
\hline \multicolumn{8}{|l|}{ Occipital } \\
\hline Inferior extrastriate & $12.25^{*}$ & $10.91^{*}$ & 1.12 & $11.47^{* *}$ & 1.01 & 1.68 & 1.42 \\
\hline Superior extrastriate & $6.92^{*}$ & $5.87^{*}$ & 1.52 & $11.59^{* *}$ & 0.99 & $8.84^{*}$ & 0.81 \\
\hline Calcarine fissure & 0.73 & 0.05 & NA & $8.72^{*}$ & NA & NA & NA \\
\hline Occipital pole & $8.67^{*}$ & 2.52 & NA & 1.21 & NA & NA & NA \\
\hline
\end{tabular}

Note- $d f=(1,10)$ for all comparisons. $\quad{ }^{\dagger} .05<p<.07 .{ }^{*} p<.05 . \quad{ }^{* *} p<.01 . \quad{ }^{* * *} p<.001$.
Simple $0^{\circ}$
Complex 0 ${ }^{\circ}$
Simple 90
Complex 90

\section{Dorsolateral Prefrontal Cortex (DLPFC)}
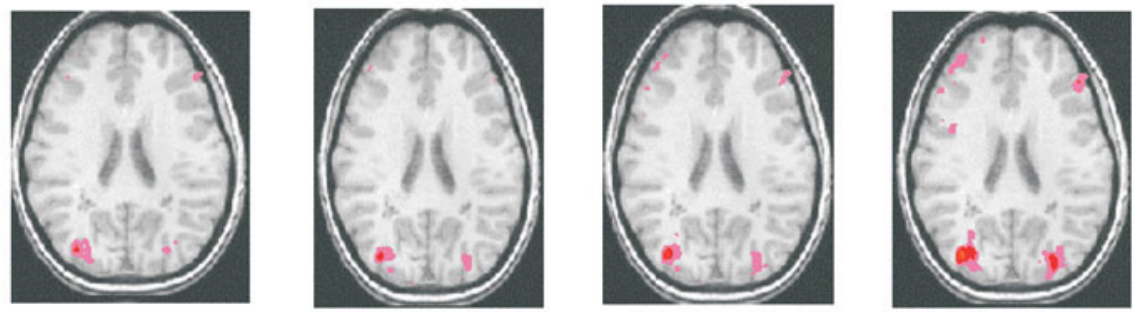

Intraparietal Sulcus (IPS)
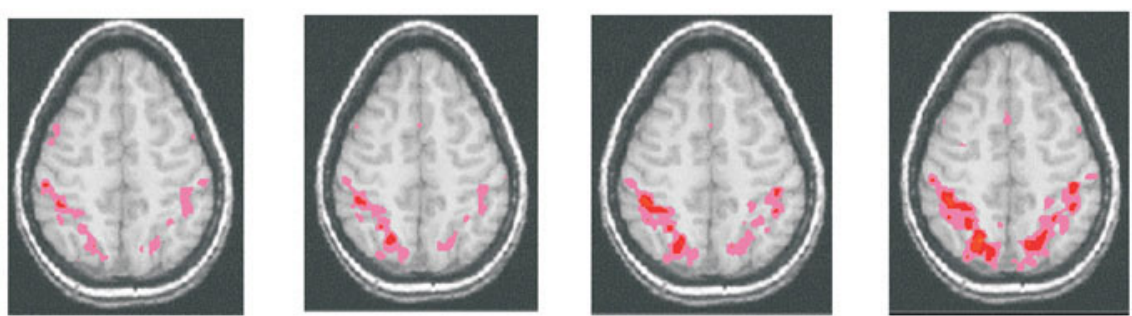

\section{Inferior Extrastriate (IES)}
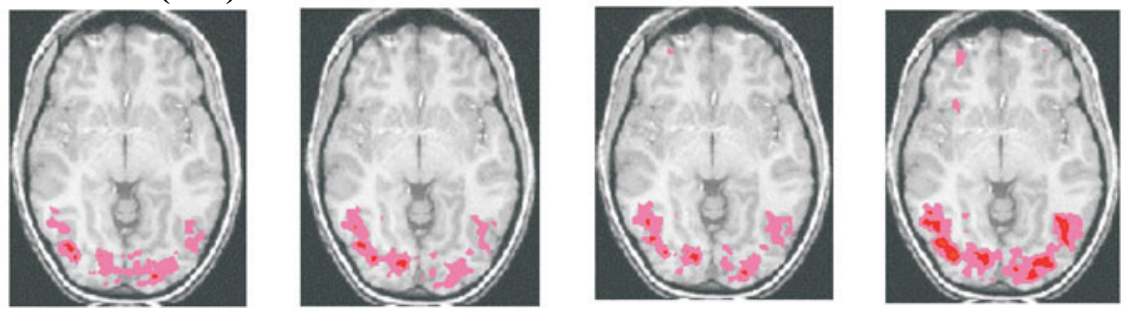

Figure 4. T-maps that were transformed to a standardized space (Talairach \& Tournoux, 1988) and averaged across participants using MCW-AFNI software (Cox, 1996) for the four experimental conditions compared with the resting baseline. For the dorsolateral prefrontal cortex (DLPFC; $x=0, y=35, z=28$ ) and the inferior extrastriate area (IES; $x=0, y=35, z=-5$ ), the activation levels were about the same for the simple $0^{\circ}$, the complex $0^{\circ}$, and the simple $90^{\circ}$ rotation conditions, but much greater for the complex $90^{\circ}$ condition, showing overadditive interaction. For the intraparietal sulcus (IPS; $x=0, y=35, z=43$ ), the overadditive interaction is apparent, in addition to an effect of rotation (greater activation for $90^{\circ}$ rotation than for $0^{\circ}$ ). 


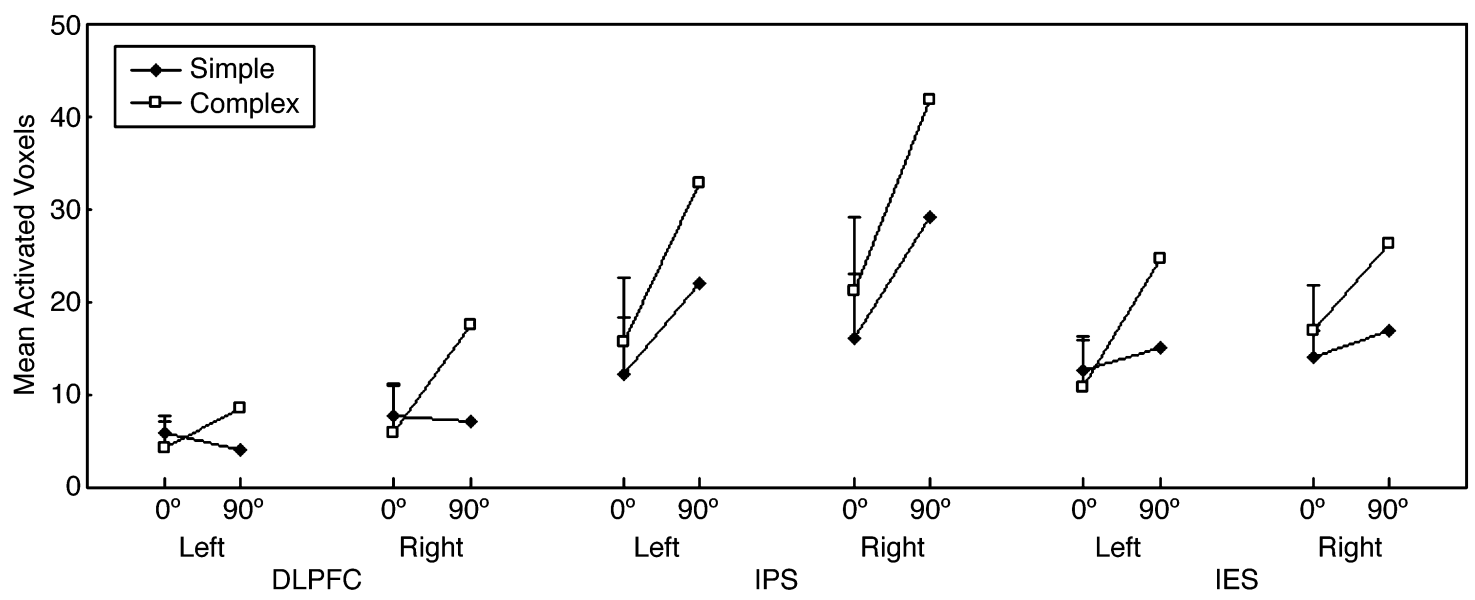

Figure 5. Mean activated voxels plotted against the amount of rotation for each hemisphere for selected regions of interest. DLPFC, dorsolateral prefrontal cortex; IPS, intraparietal sulcus; IES, inferior extrastriate.

the particular threshold we used $(t=5.0)$. Using the same ANOVA design, we found that exactly the same main effects and interactions were statistically significant as in the original analysis for the main ROIs, such as the DLPFC, the IPS, and the IES. Thus, the pattern of results was not specific to the particular threshold we chose. Also, as is shown in the Appendix, the average percentage of dsi showed a very similar pattern of results.

\section{Functional Connectivity}

The functional connectivity analysis examined which regions showed similar temporal patterns of activity. We performed a separate factor analysis for each condition, and the results showed two systematic patterns (see Figure 6). First, there were three main common factors (or clusters of regions) across conditions - namely, factors corresponding to executive processing, spatial processing, and lower level visual processing. For example, the factors in the simple $0^{\circ}$ condition are shown in the first three columns of Table 4, labeled F1, F2, and F3. The first network, corresponding to F1 in this condition, consists primarily of frontal areas, and we refer to it as a central executive network. The second network, corresponding to F2 in this condition, is composed basically of the parietal areas, and we refer to it as a spatial network. The third network, corresponding to F3 in this condition, includes mainly the occipital areas and the inferior temporal area, and we refer to this network as a lower visual network. Similar networks emerge in the remaining conditions, even though their communality values are different across the conditions. The significance of this outcome is that it shows that similar networks of ROIs that are typically associated with a particular facet of processing are extracted across conditions even with rotational indeterminacy of factor analyses. This seems to provide a way of tentatively identifying a cortical network on the basis of fMRI functional connectivities.

The second important point that emerged from the factor analysis is that the number of ROIs for each fac- tor increased, forming a larger network, as task difficulty increased. For example, in the simple $0^{\circ}$ condition, these three networks are fairly distinct from each other, without much overlap between the factors. On the other hand, in the complex $90^{\circ}$ rotation condition, the first factor is the largest of all, including the frontal, parietal, temporal, and occipital areas. The third factor also includes the parietal and occipital ROIs, covering the dorsal and ventral pathways. The integration is also supported by an increasing number of ROIs from the simple $0^{\circ}$ condition, in which the mean number of ROIs per factor is 7.3 , to the complex $90^{\circ}$ condition, in which the mean number of ROIs is 11.7.

\section{DISCUSSION}

One of the main goals of this study was to investigate the effect of figural complexity and amount of rotation on activation in the dorsal and ventral pathways in the mental rotation task. If object processing and mental rotation are independent of each other, the manipulation of figural complexity should have primarily affected the ventral what system, and the manipulation of amount of rotation should have primarily affected the dorsal where system, without an interaction between the two factors. However, the results showed an overadditive interaction in which the effect of rotation was greater for complex figures than for simple figures. Moreover, this overadditive interaction was found across the brain from the frontal to the occipital lobe. Therefore, our results indicate that both the dorsal and the ventral systems respond to the manipulations of figural complexity and mental rotation, disconfirming the independent pathway hypothesis. The results might reflect that both regions are involved in both types of processing or that an increase in task demand of one type of processing also increases the resource demand of the other type of processing.

The results also suggest that some regions are more involved in certain processes than are others, reflecting the relative specialization of cortical regions. As Table 2 

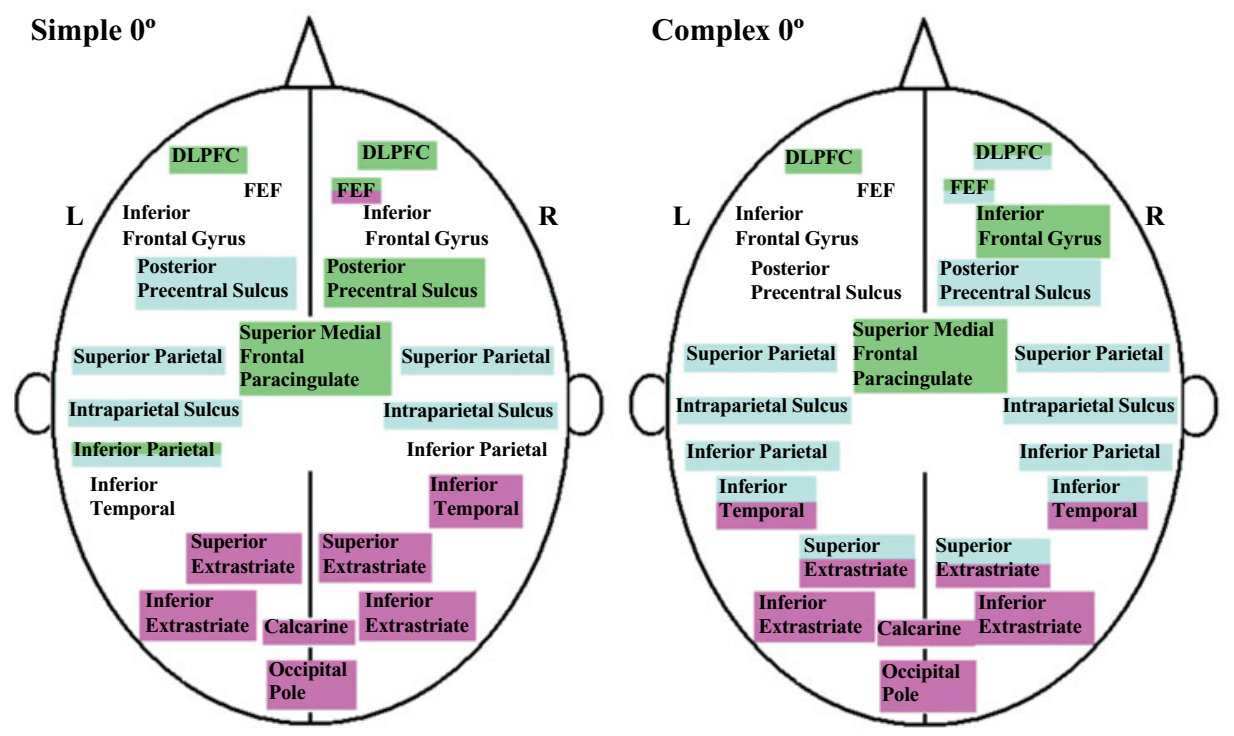

Factor 1 Central executive network Factor 2 Spatial network Factor 3 Lower visual network
Factor 1 Central executive network

Factor 2 Spatial and object working memory network Factor 3 Lower visual network

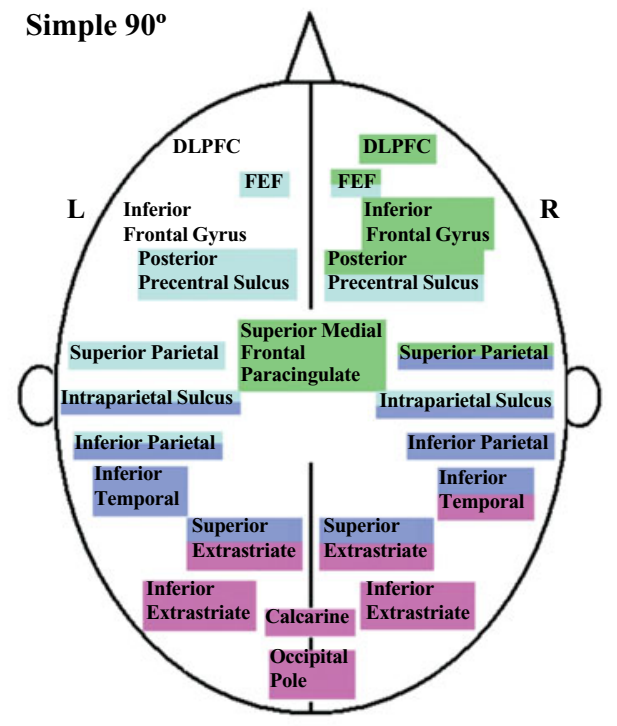

Factor 1 Central executive network

Factor 2 Spatial working memory network Factor 3 Spatial processing network Factor 4 Lower visual network

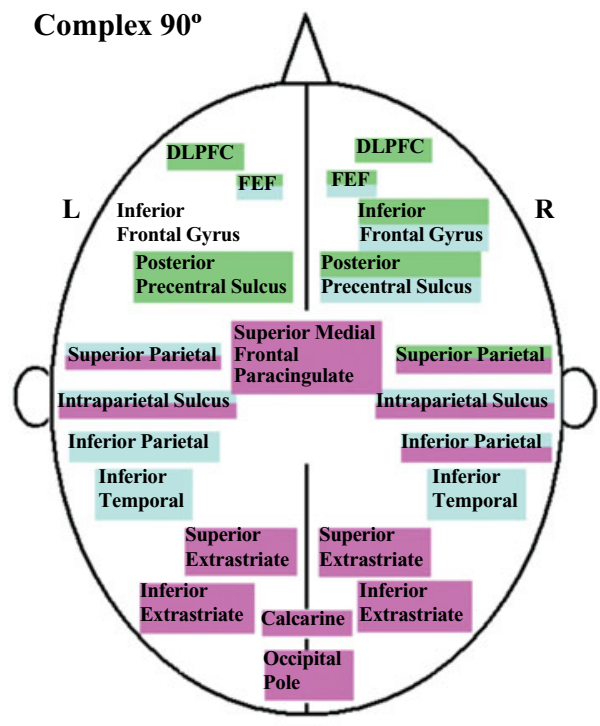

Factor 1 Central executive network Factor 2 Integrated working memory network Factor 3 Visual and spatial network

Figure 6. The results of factor analyses. The factors are rearranged to show the correspondence across the conditions, instead of the order of communality values, which are shown at the bottom of each factor in Table 4 . For the simple $0^{\circ}$, complex $0^{\circ}$, and complex $90^{\circ}$ rotation conditions, Factor 1 is the central executive network, Factor 2 corresponds to the spatial processing or spatial working memory network, and Factor 3 reflects the lower visual network. For the simple $90^{\circ}$ condition, the factor structure was slightly different, because four factors were extracted. In this condition, Factor 1 is the central executive network, Factor 2 corresponds to spatial working memory, Factor 3 reflects the spatial processing network, and Factor 4 corresponds to the lower visual network.

shows, for the frontal, temporal, and occipital regions, the effect of the amount of rotation was observed only for the complex stimuli, but not for the simple stimuli.
However, for the parietal regions, activation increased from $0^{\circ}$ to $90^{\circ}$ of rotation even for the simple stimuli, although much more so for the complex stimuli. 
Table 4

Results of Factor Analysis

\begin{tabular}{|c|c|c|c|c|c|c|c|c|c|c|c|c|c|}
\hline \multirow[b]{2}{*}{ Region } & \multicolumn{3}{|c|}{ Simple $0^{\circ}$} & \multicolumn{3}{|c|}{ Complex $0^{\circ}$} & \multicolumn{4}{|c|}{ Simple $90^{\circ}$} & \multicolumn{3}{|c|}{ Complex $90^{\circ}$} \\
\hline & $\mathrm{F} 1$ & F2 & F3 & F1 & F2 & F3 & $\mathrm{F} 1$ & $\mathrm{~F} 2$ & F3 & $\mathrm{F} 4$ & F1 & F2 & $\mathrm{F} 3$ \\
\hline \multicolumn{14}{|l|}{ Frontal } \\
\hline DLPFC (L) & .75 & & & .62 & & .53 & & & & & .81 & & \\
\hline DLPFC (R) & .74 & & & .50 & .49 & .30 & .61 & .41 & & & .72 & & \\
\hline FEF (L) & & & & & & & & .88 & & & .57 & .55 & \\
\hline FEF (R) & .46 & & .48 & .50 & .54 & & .60 & .54 & & & .57 & .54 & \\
\hline IFG (R) & & & & .58 & & & .69 & & & .30 & .54 & .45 & .31 \\
\hline PPREC (L) & .34 & .78 & & & & & & .84 & & .36 & .58 & & .38 \\
\hline PPREC (R) & .84 & & & .40 & .78 & & .49 & .63 & & .32 & .48 & .55 & .34 \\
\hline SMFP & .77 & & .30 & .73 & .37 & & .82 & & & & .32 & .35 & .42 \\
\hline \multicolumn{14}{|l|}{ Parietal } \\
\hline SPL (L) & & .65 & & & .83 & & .38 & .59 & .40 & & .37 & .56 & .49 \\
\hline SPL (R) & & .55 & .40 & & .73 & .51 & .43 & .50 & .37 & & .41 & .30 & .60 \\
\hline IPS (L) & .31 & .54 & .30 & & .81 & .31 & .36 & .57 & .56 & & .37 & .56 & .50 \\
\hline IPS (R) & .30 & .60 & .32 & & .73 & & .33 & .53 & .61 & & .38 & .56 & .57 \\
\hline IPL (L) & .46 & .49 & & & .75 & & & .62 & .50 & & & .55 & .38 \\
\hline IPL (R) & .37 & & & & .57 & & .33 & & .63 & & .31 & .45 & .46 \\
\hline SGA (L) & & .77 & & & .67 & & .36 & .55 & .51 & & & .64 & \\
\hline SGA (R) & & & & & & & .33 & & .83 & & & .78 & \\
\hline \multicolumn{14}{|l|}{ Temporal } \\
\hline IT (L) & & & & .39 & .42 & .45 & & .30 & .57 & .37 & & .59 & .47 \\
\hline IT (R) & & .34 & .51 & & .57 & .46 & .30 & .41 & .45 & .56 & & .51 & .60 \\
\hline \multicolumn{14}{|l|}{ Occipital } \\
\hline SES (L) & & & .64 & & .48 & .51 & & & .50 & .51 & & .33 & .65 \\
\hline SES (R) & & .33 & .66 & & .52 & .54 & & & .46 & .61 & & .30 & .73 \\
\hline IES (L) & & & .55 & & .34 & .60 & .30 & & & .66 & & .38 & .66 \\
\hline IES (R) & & & .70 & & .36 & .67 & & & .35 & .61 & & .34 & .71 \\
\hline CALC & & & .79 & & & .79 & & & & .85 & & & .79 \\
\hline $\mathrm{OP}$ & & & .78 & & .31 & .80 & & & & .71 & & & .77 \\
\hline Communality & 3.57 & 3.45 & 4.24 & 2.68 & 6.41 & 4.16 & 3.49 & 4.97 & 4.07 & 3.91 & 3.93 & 5.06 & 5.96 \\
\hline
\end{tabular}

Note-Boldface type indicates the factor loading values that are greater than or equal to .40 and are included in interpretation of the factor, and Roman type indicates the factor loading values that are greater than or equal to .30 but are not included in the factor. We reorganized the order of factors in the table to make the comparison across conditions easier; therefore, the factor order does not correspond to the order of communality. For the simple $0^{\circ}$ condition, Factor 1 (F1) was the central executive network, Factor 2 (F2) was the spatial network, and Factor 3 (F3) was the lower visual network. For the complex $0^{\circ}$ condition, F1 was the central executive network, F2 was the spatial and object working memory network, and F3 was the lower visual network. For the simple $90^{\circ}$ condition, F1 was the central executive network, F2 was the spatial working memory network, F3 was the spatial processing network, and F4 was the lower visual network. For the complex $90^{\circ}$ condition, F1 was the central executive network, F2 was the integrated working memory network, and F3 was the visual and spatial network. DLPFC, dorsolateral prefrontal cortex; FEF, frontal eye field; IFG, inferior frontal gyrus; PPREC, posterior precentral sulcus; SMFP, superior medial frontal paracingulate; SPL, superior parietal lobe; IPS, intraparietal sulcus; IPL, inferior parietal lobule; SGA, supramarginal gyrus; IT, inferior temporal lobule; SES, superior extrastriate; IES, inferior extrastriate; CALC, calcarine fissure; OP, occipital pole; L, left; R, right.

As was described in the introduction, similar overadditive interactions in brain activation have been found in several other domains. For example, when both lexical and syntactic processing in the comprehension of written sentences was made more demanding, there was a reliable overadditive interaction in multiple cortical loci (Keller et al., 2001). Similarly, when both sentence structure and language (native vs. second language) were more difficult in the comprehension of spoken sentences, there was a reliable overadditive interaction in multiple cortical loci (Hasegawa, Carpenter, \& Just, 2002). Therefore, this type of overadditive interaction seems to be a rather general property of the brain function.

A difference between Cooper's (1975) results and our findings points out the useful role of resource considerations. Cooper found that figural complexity did not interact with (or even affect) the rate of rotation, whereas in our study, we found an overadditive interaction in the
RT data. One possible source of this difference was the difference in the participants' familiarity with the stimulus figures. Each of Cooper's participants was practiced for two 1-h sessions and then was tested in four 1-h sessions. On the other hand, our participants were given a practice session of approximately 6 min on the day before the scan and then were tested in the scanner in a 15 -min testing session. The extended amount of practice that Cooper's participants enjoyed probably made figural encoding and mental rotation more automatic and, hence, much less resource demanding, as indicated by several measures. The error rates were lower than those in our study, the RTs were shorter, the slopes of the RTs plotted against the amount of rotation were shallower, and there was no effect of figural complexity. Since both figural encoding and mental rotation were less resource demanding, when these processes were combined, even for a large rotation angle, the overall resource requirement 
may still have been below some capacity limitation. On the other hand, in our study, the error rates were higher, the RTs were longer, and the slopes were steeper, indicating a higher level of resource demand. The overadditive relation between figural complexity and mental rotation might arise because the combination of these processes exceeded the capacity limitation at the higher level of demand (namely, the complex figures requiring $90^{\circ}$ rotation). There might be some adaptive mechanisms for dealing with such a shortage of resources, such as trading away processing time for total resource consumption (consuming resources at the maximal rate and extending the consumption over a longer period to compensate for the maximum's not being sufficient) or segmenting the task processing into sequential components that would otherwise be executed in parallel. Such mechanisms might be manifested in the brain activation as a higher level of activation for the complex figures rotated $90^{\circ}$, because of extended, cumulated resource consumption and/or additional processing steps.

Another contribution of the present study is a factor analysis of functional connectivity. Three common factor structures, or large-scale cortical networks (Mesulam, 1990, 1998), tended to appear in all the conditions: (1) an executive control network, consisting mainly of the frontal areas, (2) a spatial information processing network, consisting primarily of the parietal regions, and (3) a lower level visual network for object recognition, consisting mainly of the occipital regions and, sometimes, the inferior temporal regions. For the easier conditions, such as the simple $0^{\circ}$ rotation condition, the networks tended to be smaller, and the three networks tended to be distinct from one another. However, for the more difficult conditions, such as the complex $90^{\circ}$ rotation, these networks became larger, sharing more brain regions. For example, the spatial and the lower visual networks were relatively separated in the simple $0^{\circ}$, complex $0^{\circ}$, and simple $90^{\circ}$ rotation conditions, whereas in the complex $90^{\circ}$ rotation condition, they were grouped together and formed a single network (F3). This indicates that synchronization between the dorsal and the ventral systems increased as task difficulty increased, suggesting a possible interaction between the two systems.

The second point of this analysis was that as task difficulty increased, functional connectivity increased. As was mentioned in the Results section, the number of ROIs per factor increased as task difficulty increased, indicating that the activities of more regions of the brain were synchronized. In other words, in the more demanding conditions, many areas across the whole brain are synchronized to form the larger scale networks.

In summary, our data provide evidence against the independent pathways hypothesis. Both ventral and dorsal pathways were activated in response to both figural encoding and rotation, although the parietal regions showed more sensitivity to rotation. This suggests either that both regions are involved in both types of processing or that increases in task demand of one type of processing also increases the resource demand of the other type of processing. As cognitive load increases, not only does activation of the corresponding brain regions increase, but also functional connectivity increases among the regions that form the networks. Our results add to a growing literature that shows interactive relationships of different types of processing among multiple brain areas and correlations between areas in activation that may suggest that the neural substrates associated with various cognitive processes often function interactively.

\section{REFERENCES}

Alivisatos, B., \& Petrides, M. (1997). Functional activation of the human brain during mental rotation. Neuropsychologia, 35, 111-118.

Attneave, F., \& Arnoult, M. D. (1956). The quantitative study of shape and pattern perception. Psychological Bulletin, 53, 452-471.

Bandettini, P. A., Wong, E. C., Hinks, R. S., TikofsKy, R. S., \& HyDE, J. S. (1992). Time course EPI of human brain function during task activation. Magnetic Resonance in Medicine, 25, 390-397.

Braver, T. S., Cohen, J. D., Jonides, J., Smith, E. E., \& Noll, D. C. (1997). A parametric study of prefrontal cortex involvement in human working memory. NeuroImage, 5, 49-62.

Carpenter, P. A., Just, M. A., KelLer, T. A., Eddy, W., \& Thulborn, K. (1999). Graded functional activation in the visuospatial system with the amount of task demand. Journal of Cognitive Neuroscience, $\mathbf{1 1}$ 9-24.

Carpenter, P. A., Just, M. A., \& Reichle, E. D. (2000). Working memory and executive function: Evidence from neuroimaging. Current Opinion in Neurobiology, 10, 195-199.

CaViness, V. S., Jr., Meyer, J., MAKris, N., \& Kennedy, D. N. (1996). MRI-based topographic parcellation of human neocortex: An anatomically specified method with estimate of reliability. Journal of Cognitive Neuroscience, 8, 566-587.

Cohen, M. S., Kosslyn, S. M., Breiter, H. C., Digirolamo, G. J., Thompson, W. L., Anderson, A. K., Bookheimer, S. Y., Rosen, B. R., \& Belliveau, J. W. (1996). Changes in cortical activity during mental rotation: A mapping study using functional MRI. Brain, 119, 89-100.

COOPER, L. A. (1975). Mental rotation of random two-dimensional shapes. Cognitive Psychology, 7, 20-43.

CoOper, L. A., \& PoDGORNY, P. (1976). Mental transformations and visual comparison processes: Effects of complexity and similarity. Journal of Experimental Psychology: Human Perception \& Performance, 2, 503-514.

Cox, R. W. (1996). AFNI: Software for visualization and analysis of functional magnetic resonance neuroimages. Computers \& Biomedical Research, 29, 162-173.

D’Esposito, M., AGuirre, G. K., Zarahn, E., \& Ballard, D. (1998). Functional MRI studies of spatial and non-spatial working memory. Cognitive Brain Research, 7, 1-13.

D’Esposito, M., Postle, B., Ballard, D., \& Lease, J. (1999). Maintenance versus manipulation of information held in working memory: An event-related fMRI study. Brain \& Cognition, 41, 66-86.

Desrocher, M. E., Smith, M. L., \& TAylor, M. J. (1995). Stimulus and sex differences in performance of mental rotation: Evidence from event-related potentials. Brain \& Cognition, 28, 14-38.

Diwadkar, V. A., Carpenter, P. A., \& Just, M. A. (2000). Collaborative activity between parietal and dorso-lateral prefrontal cortex in dynamic spatial working memory revealed by fMRI. NeuroImage, 12, 85-99.

EDDY, W. F., Fitzgerald, M., Genovese, C. R., Mockus, A., \& Noll, D. C. (1996). Functional imaging analysis software - computational olio. In A. Prat (Ed.), Proceedings in computational statistics (pp. 3949). Heidelberg: Physica-Verlag.

FARAH, M. J. (1990). Visual agnosia. Cambridge, MA: MIT Press.

Friston, K. J. (1994). Functional and effective connectivity: A synthesis. Human Brain Mapping, 2, 56-78. 
Friston, K. J., Frith, C. D., Liddle, P. F., \& Frackowiak, R. S. J. (1993). Functional connectivity: The principal-component analysis of large PET data sets. Journal of Cerebral Blood Flow \& Metabolism, 13, 5-14.

Grasby, P. M., Frith, C. D., Friston, K. J., Simpson, J., Fletcher, P. C., FrackowiaK, R. S. J., \& Dolan, R. J. (1994). A graded task approach to the functional mapping of brain areas implicated in auditoryverbal memory. Brain, 117, 1271-1282.

Hasegawa, M., Carpenter, P. A., \& Just, M. A. (2002). An fMrI study of bilingual sentence comprehension and workload. NeuroImage, 15, 647-660.

Just, M. A., Carpenter, P. A., Keller, T. A., Eddy, W. F., \& ThulBORN, K. R. (1996). Brain activation modulated by sentence comprehension. Science, 274, 114-116.

Just, M. A., Carpenter, P. A., Maguire, M., Diwadkar, V., \& MCMAINs, S. (2001). Mental rotation of objects retrieved from memory: A functional MRI study of spatial processing. Journal of Experimental Psychology: General, 130, 493-504.

Just, M. A., Carpenter, P. A., \& Varma, S. (1999). Computational modeling of high-level cognition and brain function. Human Brain Mapping, 8, 128-136.

KAnwisher, N., Chun, M. M., McDermott, J., \& Ledden, P. J. (1996). Functional imaging of human visual recognition. Cognitive Brain Research, 5, 55-67.

Keller, T. A., CARpenter, P. A., \& Just, M. A. (2001). The neural bases of sentence comprehension: A fMRI examination of syntactic and lexical processing. Cerebral Cortex, 11, 223-237.

Kwong, K. K., Belliveau, J. W., Chesler, D. A., Goldberg, I. E., Weisskoff, R. M., Poncelet, B. P., Kennedy, D. N., Hoppel, B. E., Cohen, M. S., Turner, R., Cheng, H.-M., Brady, T. J., \& Rosen, B. R. (1992). Dynamic magnetic resonance imaging of human brain activity during primary sensory stimulation. Proceedings of the $\mathrm{Na}$ tional Academy of Sciences, 89, 5675-5679.

Lazar, N. A., EdDY, W. F., GeNovese, C. R., \& Welling, J. S. (2001). Statistical issues in fMRI for brain imaging. International Statistical Review, 69, 105-127.

Levy, R., \& Goldman-Rakic, P. S. (2000). Segregation of working memory functions within the dorsolateral prefrontal cortex. Experimental Brain Research, 133, 23-32.

Logothetis, N. K., Pauls, J., \& Poggio, T. (1995). Shape representation in the inferior temporal cortex of monkeys. Current Biology, $\mathbf{5}_{2}$ 552-563.

Malach, R., Reppas, J. B., Benson, R. R., Kwong, K. K., Jiang, H., Kennedy, W. A., Ledden, P. J., Brady, T. J., Rosen, B. R., \& Tootell, R. B. H. (1995). Object-related activity revealed by functional magnetic resonance imaging in human occipital cortex. Proceedings of the National Academy of Sciences, 92, 8135-8139.

McInTosh, A. R., \& Gonzalez-LimA, F. (1994). Structural equation modeling and its application to network analysis in functional brain imaging. Human Brain Mapping, 2, 2-22.

Mesulam, M.-M. (1990). Large-scale neurocognitive networks and distributed processing for attention, language and memory. Annals of Neurology, 28, 597-613.

Mesulam, M.-M. (1998). From sensation to cognition. Brain, 121, 1013-1052.

Miller, E. K., Erikson, C. A., \& Desimone, R. (1996). Neural mech- anisms of visual working memory in prefrontal cortex of the macaque. Journal of Neuroscience, 16, 5154-5167.

MishKin, M., Ungerleider, L. G., \& MACKo, K. A. (1983). Object vision and spatial vision: Two cortical pathways. Trends in Neurosciences, 6, 414-417.

OGAWA, S., LeE, T. M., Kay, A. R., \& TANK, D. W. (1990). Brain magnetic resonance imaging with contrast dependent on blood oxygenation. Proceedings of the National Academy of Sciences, 87, 98689872.

Owen, A. M., Stern, C. E., Look, R. B., Tracey, I., Rosen, B. R., \& Petrides, M. (1998). Functional organization of spatial and nonspatial working memory processing within the human lateral frontal cortex. Proceedings of the National Academy of Sciences, 95, 77217726.

Peronnet, F., \& Farah, M. J. (1989). Mental rotation: An eventrelated potential study with a validated mental rotation task. $\underline{\text { Brain } \&}$ Cognition, 9, 279-288.

Peterson, B. S., Skudlarski, P., Gatenby, J. C., Zhang, H., Anderson, A. W., \& Gore, J. C. (1999). An fMRI study of Stroop word-color interference: Evidence for cingulate subregions subserving multiple distributed attentional systems. Biological Psychiatry, 45, 12371258.

Petrides, M. (1994). Frontal lobes and working memory: Evidence from investigations of the effects of cortical excisions in nonhuman primates. In F. Boller \& J. Grafman (Eds.), Handbook of neuropsychology (Vol. 9, pp. 59-82). Amsterdam: Elsevier.

Rademacher, J., Galaburda, A. M., Kennedy, D. N., FilipeK, P. A., \& CAVINESS, V. S., JR. (1992). Human cerebral cortex: Localization, parcellation, and morphometry with magnetic resonance imaging. Journal of Cognitive Neuroscience, 4, 352-374.

ShePARD, R. N., \& Metzler, J. (1971). Mental rotation of threedimensional objects. Science, 171, 701-703.

Smith, E. E., Jonides, J., \& KoEPPE, R. A. (1996). Dissociating verbal and spatial working memory using PET. Cerebral Cortex, 6, 11-20.

Tagaris, G. A., Kim, S.-G., Strupp, J. P., Andersen, P., Ugurbil, K., \& Georgopoulos, A. P. (1997). Mental rotation studied by functional magnetic resonance imaging at high field (4 tesla): Performance and cortical activation. Journal of Cognitive Neuroscience, $\mathbf{9}_{2}$ 419-432.

TALAIRACH, J., \& Tournoux, P. (1988). Co-planar stereotaxic atlas of the human brain. New York: Thieme.

Thulborn, K. R., Voyvodic, J., McCurtain, B., Gillen, J., Chang, S., Just, M. A., Carpenter, P. A., \& Sweeney, J. A. (1996). High field functional MRI in humans: Applications to cognitive function. In P. P. Pavone \& P. Rossi (Eds.), Proceedings of the European Seminars on Diagnostic and Interventional Imaging (Syllabus 4, pp. 91-96). New York: Springer-Verlag.

UngerleIDER, L. G., \& HAXBy, J. V. (1994). "What" and "where" in the human brain. Current Opinion in Neurobiology, 4, 157-165.

Ungerleider, L. G., \& MishKIN, M. (1982). Two cortical visual systems. In D. J. Ingle, M. A. Goodale, \& R. J. W. Mansfield (Eds.), The analysis of visual behavior (pp. 549-586). Cambridge, MA: MIT Press.

Wijers, A. A., Otten, L. J., Feenstra, S., Mulder, G., \& Mulder, L. J. M. (1989). Brain potentials during selective attention, memory search, and mental rotation. Psychophysiology, 26, 452-467. 


\section{APPENDIX}

Results of the Analysis, With the Percentage of Difference in Signal Intensity (dsi)

\section{Manipulation: dsi, 2 (Amount) $\times 2$ (Complexity) $\times 2$ (Hemisphere)}

Interactive relationship between object recognition and mental rotation. The data are shown in Table A1, and the ANOVA results are shown in Table A2. Many ROIs showed the same tendency toward the overadditive interaction between amount of rotation and complexity as the voxel count data (e.g., the DLPFC, the FEF, the IFG, the PPREC, the IPS, the IT, and the SES), although they did not reach statistical significance except for the SES $[F(1,10)=9.30, p<.05]$. The CALC showed an interaction, in which the activation was higher for simple stimuli than for complex stimuli for $0^{\circ}$ of rotation, whereas this relationship was reversed for $90^{\circ}$.

Hemispheric difference. Most ROIs showed bilateral activation, although some ROIs showed hemispheric differences (the FEF, the IFG, and the IES out of 10 ROIs). The right hemisphere showed greater percentage of signal intensity change for the FEF $[F(1,7)=10.52, p<.01]$ and the IFG $[F(1,9)=10.42, p<.01]$. An interaction was found for IFG, in which the effect of degree of rotation was greater for the right hemisphere than for the left hemisphere $[F(1,9)=5.50, p<.05]$.

The IES showed a significant three-way interaction, in which the complexity effect was greater for $90^{\circ}$ of rotation than for $0^{\circ}$ for the left hemisphere, whereas the complexity effect remained constant across the two levels of rotation for the right hemisphere.

Table A1

Mean Difference in Signal Intensity for Conditions for Each Region of Interest

\begin{tabular}{|c|c|c|c|c|c|c|c|c|}
\hline \multirow[b]{2}{*}{ Region } & \multicolumn{4}{|c|}{ Left Hemisphere } & \multicolumn{4}{|c|}{ Right Hemisphere } \\
\hline & $\mathrm{S}^{\circ}$ & $\mathrm{C}^{\circ}$ & $\mathrm{S} 90^{\circ}$ & $\mathrm{C} 90^{\circ}$ & $\mathrm{S}^{\circ}$ & $\mathrm{C}^{\circ}$ & $\mathrm{S} 90^{\circ}$ & $\mathrm{C} 90^{\circ}$ \\
\hline \multicolumn{9}{|l|}{ Frontal } \\
\hline Dorsolateral prefrontal cortex & 1.0 & 0.9 & 1.0 & 1.3 & 1.1 & 1.1 & 1.3 & 1.7 \\
\hline Frontal eye field & 1.1 & 1.2 & 1.4 & 1.7 & 1.7 & 1.8 & 1.8 & 2.2 \\
\hline Inferior frontal gyrus & 0.9 & 0.9 & 1.0 & 1.1 & 1.1 & 1.3 & 1.4 & 1.8 \\
\hline Posterior precentral sulcus & 0.9 & 1.0 & 1.4 & 1.6 & 1.2 & 1.3 & 1.6 & 1.9 \\
\hline Supplementary motor area & 0.5 & 1.1 & 1.3 & 1.6 & & & & \\
\hline Superior medial frontal paracingulate & 0.9 & 1.1 & 1.1 & 1.4 & & & & \\
\hline \multicolumn{9}{|l|}{ Parietal } \\
\hline Inferior parietal lobule & 0.9 & 1.1 & 1.3 & 1.4 & 1.0 & 1.1 & 1.2 & 1.4 \\
\hline Intraparietal sulcus & 1.1 & 1.3 & 1.5 & 1.9 & 1.1 & 1.3 & 1.5 & 1.9 \\
\hline Superior parietal lobule & 0.9 & 1.3 & 1.6 & 2.0 & 1.0 & 1.2 & 1.5 & 1.8 \\
\hline \multicolumn{9}{|l|}{ Temporal } \\
\hline Inferior temporal lobule & 1.1 & 0.9 & 1.2 & 1.6 & 1.1 & 1.3 & 1.4 & 1.7 \\
\hline \multicolumn{9}{|l|}{ Occipital } \\
\hline Inferior extrastriate & 1.5 & 1.3 & 1.5 & 2.0 & 1.3 & 1.6 & 1.6 & 1.9 \\
\hline Superior extrastriate & 1.5 & 1.4 & 1.6 & 2.1 & 1.5 & 1.5 & 1.5 & 1.8 \\
\hline Calcarine fissure & 1.8 & 1.7 & 1.7 & 1.8 & & & & \\
\hline Occipital pole & 1.6 & 1.8 & 1.8 & 2.1 & & & & \\
\hline
\end{tabular}

Table A2

$F$ Values of Analyses of Variance on the Percentage of Signal Intensity (dsi; Amount [2] $\times$ Complexity [2] $\times$ Hemisphere [2])

\begin{tabular}{lcccccccc}
\hline \multicolumn{1}{c}{ Region } & $d f$ & Amount & Complexity & Hemisphere & $\mathrm{A} \times \mathrm{C}$ & $\mathrm{A} \times \mathrm{H}$ & $\mathrm{C} \times \mathrm{H}$ & $\mathrm{A} \times \mathrm{C} \times \mathrm{H}$ \\
\hline Frontal & & & & & & & & \\
$\quad$ Dorsolateral prefrontal cortex & 1,10 & $13.81^{* *}$ & 1.85 & 3.83 & 2.16 & 2.58 & 2.02 & 0.04 \\
$\quad$ Frontal eye field & 1,7 & 3.65 & $8.9^{*}$ & $10.52^{*}$ & 2.74 & 0.00 & 2.48 & 1.82 \\
$\quad$ Inferior frontal gyrus & 1,9 & $6.53^{*}$ & $4.65^{\dagger}$ & $10.42^{*}$ & 0.60 & $5.5^{*}$ & 2.78 & 0.05 \\
$\quad$ Posterior precentral sulcus & 1,6 & $6.62^{*}$ & $13.21^{*}$ & 1.46 & 1.98 & 0.07 & 1.14 & 0.10 \\
$\quad$ Supplementary motor area & 1,6 & $14.21^{* *}$ & $17.78^{* *}$ & $\mathrm{NA}$ & 0.92 & $\mathrm{NA}$ & $\mathrm{NA}$ & $\mathrm{NA}$ \\
$\quad$ Superior medial frontal paracingulate & 1,9 & 3.98 & $6.3^{*}$ & $\mathrm{NA}$ & 0.04 & $\mathrm{NA}$ & $\mathrm{NA}$ & $\mathrm{NA}$ \\
Parietal & & & & & & & & \\
$\quad$ Inferior parietal lobule & 1,10 & $13.36^{* *}$ & $15.20^{* *}$ & 0.01 & 0.01 & 1.47 & 0.78 & 0.41 \\
$\quad$ Intraparietal sulcus & 1,10 & $53.93^{* * *}$ & $24.64^{* * *}$ & 0.36 & 2.02 & 0.43 & 0.52 & 1.98 \\
$\quad$ Superior parietal lobule & 1,9 & $43.38^{* * *}$ & $37.71^{* * *}$ & 1.10 & 0.00 & 2.26 & 3.10 & 0.59 \\
Temporal & & & & & & & & \\
$\quad$ Inferior temporal lobule & 1,10 & $17.31^{*}$ & $17.33^{*}$ & 2.91 & 3.17 & 0.56 & 1.64 & 3.62 \\
Occipital & & & & & & & \\
$\quad$ Inferior extrastriate & 1,10 & $7.2^{*}$ & $7.97^{*}$ & 0.03 & $6.39^{*}$ & 0.01 & 3.57 & $5.4^{*}$ \\
$\quad$ Superior extrastriate & 1,10 & $23.37^{* * *}$ & $6.4^{*}$ & 0.10 & $9.30^{*}$ & 3.22 & 1.91 & 0.40 \\
$\quad$ Calcarine fissure & 1,10 & 0.30 & 0.03 & $\mathrm{NA}$ & $14.20^{* *}$ & $\mathrm{NA}$ & $\mathrm{NA}$ & $\mathrm{NA}$ \\
$\quad$ Occipital pole & 1,9 & $6.16^{*}$ & $7.43^{*}$ & $\mathrm{NA}$ & 0.14 & $\mathrm{NA}$ & $\mathrm{NA}$ & $\mathrm{NA}$ \\
\hline
\end{tabular}

${ }_{\dagger}^{\dagger} 05<p<.07 . \quad{ }^{*} p<.05 . \quad{ }^{* *} p<.01 . \quad{ }^{* * *} p<.001$. 